\section{SOI: $1.1 / \mathrm{TAS} \quad$ DOI: $10.15863 / \mathrm{TAS}$ International Scientific Journal Theoretical \& Applied Science}

\author{
p-ISSN: 2308-4944 (print) e-ISSN: 2409-0085 (online) \\ Year: $2016 \quad$ Issue: 2 Volume: 34 \\ Published: 29.02.2016 $\underline{\text { http://T-Science.org }}$
}

\section{Zhanna Amangeldinovna Khamzina doctor of Law, professor of the Kazakh National Pedagogical University named after Abay $\underline{\text { notarius-almaty@ rambler.ru }}$}

Yermek Abiltayevich Buribayev doctor of Law, associate professor of the Kazakh National Pedagogical University named after Abay ermek_a@rambler.ru

SECTION 32. Jurisprudence.

\title{
ISSUES OF SOCIAL PROTECTION OF FAMILY AND CHILD IN KAZAKHSTAN
}

\begin{abstract}
The relevance of the research issue is conditioned by state and society' being interested in provision of social support to families, especially with regard to addressing the problems of poverty. There had been made conclusions that we need a complex state approach, development of a special State Program on supporting families; the concept of having many children shall be revised. It was proposed to consider as large families only those families, in which there are three or more minor children. There were justified statements on insufficiency of the existing norms and measures of large families' social safety net. It was proposed to increase the level of their social security up to the minimum wage.

Key words: family, child, social protection, social security, social standard.

Language: Russian

Citation: Khamzina ZA, Buribayev YA (2016) ISSUES OF SOCIAL PROTECTION OF FAMILY AND CHILD IN KAZAKHSTAN. ISJ Theoretical \& Applied Science, 02 (34): 42-48.

Soi: $\underline{\text { http://s-o-i.org/1.1/TAS-02-34-7 Doi: crossef http://dx.doi.org/10.15863/TAS.2016.02.34.7 }}$

\section{ВОПРОСЫ СОЦИАЛЬНОЙ ЗАЩИТЫ СЕМЬИ И РЕБЕНКА В КАЗАХСТАНЕ}

Аннотация: Актуальность темы исследования обусловлена интересами государства и общества $в$ оказании социальной поддержки семей, в особенности в отношении решения проблем бедности. Сделаны выводы о том, что требуется комплексный государственный подход, разработка специальной Государственной программы по поддержке семей, обоснованы тезисы о недостаточности существующих форм и мер социальной защиты многодетных семей. Предложено поднять уровень их социального обеспечения до прожиточного минимума.
\end{abstract}

Ключевые слова: семья, ребенок, социильная защчита, социальное обеспечение, сочииальный стандарт.

В казахстанском обществе социальноэкономические процессы, сопровождающиеся снижением среднедушевых номинальных денежных доходов населения, замедлением роста ВВП, подъемом индекса потребительских цен, значительным увеличением уровня инфляции, являются проявлением в национальных условиях общемирового замедления экономического роста, значительного спада цен на энергоресурсы, металлы. В Казахстане доля населения с доходом 2,5 доллара США по паритету покупательской способности в день неуклонно падала последние 15 лет с 14,3 \% в 2001 году до 0,1 \% населения в 2014 году [1], то в 2015-2016 гг. вследствие перехода к свободному курсообразованию валют и инфляционному третированию неизбежно происходит увеличение указанного универсального индикатора уровня жизни на фоне замедления повышения доходов населения. В этих неблагоприятных экономических условиях в государстве не должен быть потерян, начавшийся с начала 2000-х годов, темп естественного прироста населения, который в процентном выражении имеет четкую тенденцию к увеличению, что предопределяет особую актуальность социальной защиты семьи и детей. Казахстан только в последние три года (20132015 гг.) достиг уровня параметров естественного прироста населения, количества заключенных браков, имевших место на период 1990-1991 гг. На момент образования Республики Казахстан в стране проживало 16358222 человек, указанная численность населения была достигнута только в 2011 году. На 1991 год в Казахстане насчитывалось 165498 браков, сравнимый с приведенной цифрой показатель был в 
последующем достигнут в 2012 году, особую тревогу вызывает снижение в последние 2 года (2014-2015 гг.) количества браков [2]. В Казахстане остается на стабильно высоком уровне число детей с особыми потребностями, в том числе инвалидов: в 2010 году - 149043 ребенка, в 2012 году- 148652, в 2014 - 141952 ребенка [3]. Ценностные ориентации детей и подростков во многом определяются уровнем материального положения их семей. Между тем положение многих казахстанских семей, имеющих детей, в современных условиях можно охарактеризовать как кризисное. Многодетные семьи, одинокие матери, семьи с детьмиинвалидами, студенческие семьи традиционно относятся к самой необеспеченной категории населения. Для абсолютного большинства семей с детьми основным источником доходов остается заработная плата. Между тем только за последний год ее реальная покупательская способность снизилась в разы, а также значительно обесценились денежные сбережения семей, хранящихся в национальной валюте. Исходя из значения и цели предоставления, социальные пособия многодетным семьям должны занимать значительную долю в доходах этих семей. Однако во многом уровень жизни малообеспеченных семей с детьми не претерпевает положительных качественных изменений, поскольку пособие многодетным семьям индексируется в очень ограниченном размере. Например, специальное государственное пособие многодетным семьям, имеющим четырех и более совместно проживающих несовершеннолетних детей, в том числе детей, обучающихся по очной форме обучения в организациях среднего, технического и профессионального, послесреднего образования, высших учебных заведениях, после достижения ими совершеннолетия до времени окончания ими учебных заведений (но не более чем до достижения двадцатитрехлетнего возраста) составляет 4,16 месячного расчетного показателя (независимо от фактического числа детей, воспитывающихся в семье), в денежном выражении 8245 тенге - в 2015 году, 8823 тенге 2016 году, индексация составила 7 \%, при официальном уровне инфляции в 2015 году 13,6 $\%$ [4]. Указанный формат индексации составляет меньший размер, чем ежегодное увеличение размера пенсии и заработных плат, в целом от одной индексации до другой сокращается в реальном выражении размер пособия многодетным семьям. При этом параметры пособия не дифференцируется в зависимости от числа детей, воспитывающихся в семье: четверо или восемь детей, оно назначается в одном и том же размере. Если в семье 4 ребенка, то фактически на каждого пособие буде составлять
1,04 МРП, а если 8, то 0,52 МРП.Что же касается семей, имеющих высокий достаток, то здесь эти пособия и имеющиеся в законодательстве льготы для многодетных семей тем более не играют никакой роли в определении уровня их жизни. Анализ системы пособий, льгот и компенсационных выплат семье позволяет констатировать, что их роль в уровне материального благосостояния, уровне социальной и экономической эффективности защиты семьи крайне невелика [5]. В Казахстане наряду с бездифференцированным подходом к социальной помощи семьям с детьми предусматривается адресная форма пособий, в виде пособия на детей в случаях, когда среднедушевой доход семьи ниже стоимости продовольственной корзины. То есть данный вид социальной помощи предназначен для детей из действительно бедных семей, чей доход составляет $60 \%$ и менее прожиточного минимума (прожиточный минимум состоит из суммы стоимости продовольственной корзины и фиксированной доли расходов на непродовольственные товары и услуги, последнее значение на протяжении последних 15 лет определяется в размере $40 \%$ к стоимости минимальной потребительской корзины в свою очередь равной прожиточному минимуму). По итогам 9 месяцев 2015 г. пособием на детей до 18 лет из малообеспеченных семей охвачено 519,3 тыс. детей, что меньше на 2,8 \% по сравнению с аналогичным периодом 2014 года, при этом сумма назначений составила 7,6 млрд. тенге. Следует отметить, что из общей суммы выплаченных пособий на детей - 72,6 \% направлено детям, проживающим в сельской местности, их доля составила 71,2 \%. По состоянию на 1 октября 2015 года адресная социальная помощь назначена 34,7 тыс. гражданам с доходами ниже черты бедности на сумму 752,2 млн тенге. Наибольший удельный вес среди получателей АСП занимают дети - 66,2 $\%$, что в сравнении с аналогичным периодом прошлого года больше на 31,0 \% [6]. Анализ социальной поддержки многодетных семей и структуры бедности позволяют аргументировать в пользу того, что у казахстанской бедности детское лицо. Именно многодетные семьи, как правило, являются представителями «традиционно бедных» семей. Однако большой удельный вес среди бедных домохозяйств составляют и так называемые «новые бедные» семьи, чей низкий уровень жизни обусловлен низким уровнем заработной платы, безработицей трудоспособных членов семьи. Немаловажная роль в этом случае отводится ситуации на рынке труда, которая и предопределяет доступность к заработкам у работающих родителей. В этой связи политика в области регулирования 
трудовых отношений должна быть ориентирована на первоочередное предоставление работы многодетным родителям, расширение практики гибкого режима труда работающим матерям, что не было, на мой взгляд учтено при разработке нового Трудового кодекса РК от 23 ноября 2015 года № 414-V ЗРК [7]. Неполные семьи также составляют уязвимую группу с точки зрения бедности. Вместе с тем, даже появление второго ребенка в полной семье повышает риск бедности до 50\%. Меры, предпринимаемые казахстанским правительством в направлении поддержки семьи и женщин, имеющих детей носят разнонаправленный характер: с одной стороны с 2012 года ограничены размеры выплат по беременности родам из ГФСС, с другой происходит увеличение размера пособий и страховых выплат по уходу за ребенком пропорционально ежемесячному росту МРП; с одной стороны сокращаются гарантии социально-трудовых прав женщин, лиц с семейными обязанностями, а с другой пропорционально МРП растет пособие на рождение ребенка. С 1 января 2018 года произойдет кардинальное изменение подхода к формированию мер материальной социальной поддержки многодетных семей: вместо ныне предоставляемых трех видов социальных выплат (специального государственного пособия для многодетных семей, государственного пособия семьям, имеющим детей, адресной социальной помощи) будет внедрена единая адресная помощь нового формата. Суть ее заключается в том, что адресная социальная помощь для семьи, имеющей трудоспособных членов будет предоставляться в случае их участия в программах занятости. Таким образом, государство снимет с себя бремя социальной материальной поддержки многодетной семьи (семьи, воспитывающей 4-х более совместно проживаемых несовершеннолетних детей). Данный социальный факт - многодетность перестанет являться таковым, выйдет их перечня социальных рисков всвязи с которыми предоставляются формы социального обеспечения. Законодательство сохранит лишь безусловную помощь в виде пособия многодетным матерям, награжденным подвесками «Алтын алқа», «Күміс алқа» или получившим ранее звание «Мать-героиня», награжденным орденами «Материнская слава» I и II степени. В соответствии с положениями Закона Республики Казахстан от 28 октября 2015 года № 369-V ЗРК «О внесении изменений и дополнений в некоторые законодательные акты Республики Казахстан по вопросам социальной защиты населения» с 1 января 2018 года многодетные семьи исключаются из числа субъектов, претендующих на социальные пособия. Семьи, чей доход ниже черты бедности, смогут обращаться на общих основаниях за назначением адресной социальной помощи, которая c указанной даты будет носить обусловленный характер, то есть трудоспособные члены таких семей должны будут принимать обязательное участие в мерах содействия занятости. Приведенное требование не распространяется на несовершеннолетних детей, в том числе детей, обучающихся по очной форме обучения в организациях среднего, технического и профессионального, послесреднего образования, высших учебных заведениях, после достижения ими совершеннолетия до времени окончания ими учебных заведений (но не более чем до достижения двадцатитрехлетнего возраста). Участие в мерах содействия занятости не будет являться обязательным условием для выплаты обусловленной денежной помощи: учащимся, студентам, слушателям, курсантам и магистрантам очной формы обучения; лицам, осуществляющим уход за детьми до семи лет, ребенком-инвалидом, инвалидами первой и второй групп, престарелыми старше восьмидесяти лет, которые нуждаются в постороннем уходе и помощи. При этом в случаях первичного выявления невыполнения обязательств по социальному контракту размер обусловленной денежной помощи всем членам семьи старше восемнадцати лет, за исключением обучающихся по очной форме обучения в организациях среднего, технического и профессионального, послесреднего образования, высших учебных заведениях, после достижения ими совершеннолетия до времени окончания ими учебных заведений (но не более чем до достижения двадцатитрехлетнего возраста) сокращается в течение месяца на пятьдесят процентов, при повторном выявлении невыполнения обязательств выплата обусловленной денежной помощи прекращается, кроме несовершеннолетних детей, в том числе обучающихся по очной форме обучения в организациях среднего, технического и профессионального, послесреднего образования, высших учебных заведениях, после достижения ими совершеннолетия до времени окончания ими учебных заведений (но не более чем до достижения двадцатитрехлетнего возраста). Таким образом, если даже родители не будут участвовать в соответствующих мерах занятости, то адресная помощь будет выплачиваться семье, состав которой в целях адресной поддержки будет включать в себя только детей. При этом, естественно, что денежные средства будут расходоваться родителями по своему усмотрению: суммарно - на нужды семьи, адресно - на детские потребности или специфические цели родителей. Соответственно 
уровень жизни детей, проживающих в малообеспеченных семьях, еще больше упадет, а предоставляемая адресная помощь не обеспечит стимулирование участия родителей детей в активных мерах занятости. В результате при иждивенческом поведении родителей тяжелое материальное положение детей еще больше будет усугубляться. Данный важнейший аспект не учтен при разработке нового подхода к назначению и выплате адресной помощи, требует повторного рассмотрения уже принятых изменений в социальное законодательство. В противном случае исключение гарантированных социальных пособий многодетным семьям вкупе с лишением возможности получения родителями адресной помощи без активного участия в мерах по занятости, приведет к переводу получаемой помощи детьми в разряд основного и единственного источника средств к существованию всей семьи. В конечном счете не будет в полной мере решен вопрос внедрения активной формы участия в системе социальной помощи, а родители с иждивенческой позицией будут существовать на социальные выплаты, предоставляемые детям. Таким образом, после вступления в силу Закона Республики Казахстан от 28 октября 2015 года № $369-\mathrm{V}$ ЗРК «О внесении изменений и дополнений в некоторые законодательные акты Республики Казахстан по вопросам социальной защиты населения» с 1 января 2018 года, в соответствии с которым произойдет реструктуризация системы адресной социальной помощи, социального обеспечения многодетных семей, доступ бедных детей к материальным формам социального обеспечения станет более ограниченным, что усугубляется тем обстоятельством, что адресная помощь финансируется из средств местных бюджетов, а регионы, отличающиеся повышенным уровнем бедности, не смогут финансировать в полном и достаточном объеме выплаты социальной помощи, что в дальнейшем повлечет за собой только ухудшение положения проживающих в этих регионах детей. Для решения проблемы детской бедности необходимы меры комплексного характера. Прежде всего, это формирование национальных механизмов по реализации государственной политики в области поддержки семей. В данном направлении Лидером нации Н.А. Назарбаевым в рамках реализации Стратегии «Казахстан-2050»: новый политический курс состоявшегося государства даны конкретные поручения Правительству: Кардинально пересмотреть законодательство в сфере защиты материнства и детства. Реформировать систему стимулирования рождаемости и поддержки многодетности разработать комплекс мероприятий, включающий в себя материальные и нематериальные стимулы, такие как льготное налогообложение, медицинское и социальное обслуживание, предоставление новых возможностей на рынке труда и тому подобные меры. С момента постановки вышеизложенных поручений прошло более двух лет, однако данное направление работы, полагаю, Правительством не обеспечено в достаточной мере. Фактически даже не началась работа по пересмотру системы источников права, регламентирующих конституционные гарантии защиты государством материнства, детства, семьи. Не определены векторы и индикаторы такого переформатирования законодательства, нет четко выработанной стратегии и параметров оценки реформирования. Не проводится деятельность по обеспечению стимулирования рождаемости и поддержки многодетности, более того, как было выше показано, многодетность в принципе с 2018 года не будет признаваться социально значимым фактором, произошедшая перестройка трудового законодательства сократила гарантии социальнотрудовых прав лиц с семейными обязанностями. На мой взгляд, решение существующего комплекса проблем в области социальной защиты по материнству и детству требует, на первом этапе, их признания, выявления социально значимых для нашего государства и общества рисков. К таким направлениям можно отнести следующее:

1) отсутствие единой правовой базы государственной семейной политики. Принимаемые государством меры в основном адресованы индивиду и слабо учитывают интересы семьи как социального института. Термин «социальная семейная политика» в государственных документах практически не используется. Семья не выступает самостоятельным объектом государственной политики и в принимаемых на различных уровнях власти программах. Не создана единая система государственной экспертизы, обеспечивающей корректировку социальной политики и ее отдельных направлений с учетом интересов института семьи;

2) не сформированность стратегии гарантий социальной защиты семей, создания адекватной системы их поддержки, к которым можно предложить отнести:

уменьшение налогооблагаемого совокупного дохода на каждого ребенка для обоих родителей;

- снижение пенсионного возраста матеряминвалидам с детства, а также одному из родителей, осуществлявшему уход за ребенкоминвалидом;

- увеличение срока выплаты пособия по уходу за ребенком, на первом этапе - до достижения ребенком полутра лет, в 
последующем - на весь период гарантированного отпуска по уходу за ребенком;

- пересмотр системы социальных выплат по материнству и детству в целях создания гарантий их предоставления в размере не ниже прожиточного минимума и др.

Исключительно важной проблемой в отношении детей является игнорирование важнейшего фактора - стоимости рабочей силы, в соответствии с которой заработная плата должна позволять содержать иждивенца. У нас же работники с заработками ниже среднего уровня делают за счет собственного и без того скудного потребления, а со средними - могут обеспечивать себя и детей только по минимуму. Развитие рыночных отношений объективно требует решения этой проблемы, тем более что самые бедные семьи в Казахстане - это семьи с детьми, и риск стать бедным значительно увеличивается у каждого взрослого, желающего иметь ребенка. Проблема усугубляется гендерным неравенством в оплате труда, а также обстоятельством того, что в подавляющем большинстве одинокий родитель, воспитывающий ребенка - это женщина. Так, в соответствии с официальными данными по всем основным группам должностей и профессий заработная плата женщин в 2015 году была ниже заработной платы мужчин. В среднем заработная плата мужчин, работающих на должности руководителя организации, сложилась в 438 тыс. тенге, переводчика - в 228 тыс. тенге, экономиста - в 193 тыс. тенге, бухгалтера - в 155 тыс. тенге. Это в $1,2-2,0$ раза выше, чем средняя заработная плата аналогичная должностям и профессиям женщин [8]. В развитых странах в соответствии с универсальными международными стандартами в данной ситуации есть вполне объективно выстроенные решения, исходящие из сущности современных экономических отношений: расходы на детей, рассматриваются как составляющая цены труда (цены рабочей силы), которую платит предприниматель работнику по договору найма. Содержание ребенка должно обеспечиваться соответствующими размерами заработной платы и гарантированными государством социальными выплатами. Международные стандарты прав на социальное обеспечение, закрепленные в Конвенции МОТ №102 «О минимальных нормах социального обеспечения» № 102, определяют социальным риском, в связи с которым должно предоставляться семейное пособие, непосредственно ответственность лиц за содержание детей, то есть сам факт рождения ребенка, его воспитание, усыновление или удочерение являются основаниями для предоставления семейного пособия. Когда пособие состоит из периодических выплат, оно должно предоставляться в течение всей продолжительности охватываемого случая. Пособие должно предоставляться в виде: 1) либо периодических выплат подлежащим обеспечению лицам, имеющим установленный стаж; 2) либо предоставления детям (или для них) пищи, одежды, крова, условий для отдыха или ухода на дому; 3) либо сочетания видов пособия, указанных в пунктах 1) и 2). Статья 44 Конвенции №102 устанавливает общую сумму пособий по отношению к заработной плате обычного взрослого неквалифицированного работника: как минимум 3\% заработной платы указанного работника, умноженные на общее число детей, подлежащих обеспечению, либо $1,5 \%$ от этой заработной платы, умноженные на общее число детей всех жителей.

Уровень цивилизованности общества, авторитет нации должен, зависеть от того положения, которое занимают в обществе дети. Поэтому совершенно очевидно, что от меры, глубины и последовательности решения проблем семьи и детства зависит будущее нашей страны. В стратегическом для страны документа по вхождению Казахстана в число 30-ти развитых стран мира «Казахстанский путь-2050: Единая цель, единые интересы, единое будущее» Главой государства индикаторы стран Организации экономического сотрудничества и развития (ОЭСР) определены как базовые ориентиры казахстанского пути в число 30 развитых государств планеты. Лидером нации поставлена задача о внедрении в Казахстане ряда принципов и стандартов ОЭСР в том числе в развитии социальной сферы. Следует отметить, что социальные государственные расходы стран ОЭСР составили в 2014 г. в среднем 21,6\% к ВВП. В период экономических кризисов расходы на социальную поддержку растут, это сглаживает удар по населению, указывают эксперты ОЭСР. В пятерке лидеров по расходам на социальные нужды - Франция (31,9\%), Финляндия (31\%), Бельгия (30,7\%), Дания $(30,1 \%)$, Италия $(28,6 \%)$. Самый низкий уровень - в Южной Корее $(10,4 \%)$, далее Эстония (16,3\%), Исландия (16,5\%) [9]. В данном направлении следует отметить огромное отставание уровня социальных расходов к ВВП в Казахстане. В соответствии с республиканским бюджетом на 2013-2015 годы было запланировано выделить: в 2013 году - 1 триллион 360 миллиардов тенге, что составляет 3,4 процента от ВВП; в 2014 году - 1 триллион 496 миллиардов тенге или 3,8 процента от ВВП, и в 2015 году - 1 триллион 727 миллиарда тенге, или 3,2 процента от ВВП [10].

По поручению Главы государства с осени 2011 года Правительством Республики Казахстан проводится работа по вступлению Казахстана в ОЭСР. Сегодня ОЭСР - это клуб богатейших 
стран мира, в котором накоплен большой опыт по проведению сбалансированной социальноэкономической политики. Присоединение Республики Казахстан к ОЭСР предполагает приведение норм национального законодательства в соответствие со стандартами организации. Этот процесс может продолжаться несколько лет и необходим для определения степени соответствия экономических правил, юридической и институциональной структуры страны-претендента стандартам, достигнутым странами ОЭСР. В этой связи видится необходимым гармонизация социального законодательства Казахстана со стандартами стран ОЭСР, данный процесс, учитывая специфичность развития национальной системы социальной защиты РК, требует специальной аналитической работы, выработки стратегического плана работы и модернизации социальной сферы Казахстана.

В данном направлении основным параметром оценки уровня жизни стран ОЭСР является доход семьи. Эксперты ОЭСР определяют, что корректированный чистый доход домохозяйства после уплаты налогов - это количество денег после уплаты налогов, которое зарабатывает или получает семья за год. Он показывает количество денежных средств, доступных домохозяйству для приобретения услуг и товаров. Финансовое благосостояние семьи - это общая стоимость финансового состояния семьи, в том числе деньги или акции, лежащие на банковских счетах. В идеале, при определении благосостояния семьи необходимо также учитывать недвижимое имущество (например, землю и дома), однако такая информация в настоящее время доступна лишь в немногих странах ОЭСР, и при подсчете данного показателя она не была учтена.

В странах ОЭСР средний скорректированный чистый доход семьи после уплаты налогов составляет 25908 долларов США в год. За последние годы увеличился средний доход семей, а также повысилось их финансовое благосостояние во многих странах ОЭСР, особенно в Дании, Ирландии и Польше. Несмотря на общее улучшение качества жизни, некоторых слоев населения оно не коснулось, и за этот же период неравенство при распределении доходов стало более ощутимым. В некоторых странах ОЭСР, например, в Чили и Мексике, а также в Турции, США и Израиле, неравенство проявляется в большей степени при распределении доходов, чем в других странах. Скандинавские и восточно-европейские страны, наоборот, характеризуются меньшей степенью неравенства при распределении доходов. В среднем в странах ОЭСР доход наиболее обеспеченных $20 \%$ населения составляет, по оценкам, 54313 долларов США в год, а наименее обеспеченные 20\% населения живут, по оценкам, на 8496 долларов США в год [11]. Полагаю, без комментариев можно оставить уровень дохода населения в Казахстане в сравнении с выше приведенными цифрами, который в выражении среднедушевого номинального денежного дохода населения составляет за 12 месяцев 2015 года немногим менее 800 тыс. тенге [12, с. 49], что на момент подготовки к публикации настоящего материала составляет около 2300 долларов США.

Таким образом, государства ОЭСР задают действительно высокие стандарты оценки уровня жизни гражданина, семьи. В данном направлении государственная социальная политика Казахстана должна быть ориентирована на повышение уровня доходов казахстанцев, что, в первую очередь, определяет состояние материального положения детей в обществе. С другой стороны, государственные социальные стандарты жизни должны обеспечивать минимальные равные возможности для материального обеспечения каждому ребенку независимо от уровня доходов семьи. С последней позиции востребованы безусловные социальные выплаты, право на которые должна детерминировать ответственность за воспитание и содержание ребенка.

References:

1. (2016) Dolja naselenija s dohodom po paritetu pokupatel'noj sposobnosti menee: 1 dollara SSHA po PPS v den'; 2,5 dollarov SSHA po PPS v den'; 5 dollarov SSHA po PPS v den'. Available:

www.stat.gov.kz/faces/wcnav externalId/home GenderCel1?_afrLoop=26195861890110168\# \%40\%3F_afrLoop\%3D26195861890110168\%2
6_adf.ctrl-state\%3D59cnknyou_63 (Accessed: 10.02.2016).

2. (2016) Dinamika demograficheskih pokazatelej naselenija Respubliki Kazahstan. Available: www.stat.gov.kz/faces/wcnav_externalId/home NumbersPopulation? afrLoop $=2619672100397$ 0208\#\%40\%3F_afrLoop\%3D26196721003970 


\begin{tabular}{l|lr|ll|ll} 
& ISRA (India) & $=\mathbf{1 . 3 4 4}$ & SIS (USA) & $=\mathbf{0 . 9 1 2}$ & ICV (Poland) & $=\mathbf{6 . 6 3 0}$ \\
Impact Factor: & ISI (Dubai, UAE) $=\mathbf{0 . 8 2 9}$ & PUHIL (Russia) $=\mathbf{0 . 1 7 9}$ & PIF (India) & $=\mathbf{1 . 9 4 0}$ \\
& GIF (Australia) & $\mathbf{0 . 5 6 4}$ & ESJI (KZ) & $=\mathbf{1 . 0 4 2}$ & & \\
\hline JIF & $=\mathbf{1 . 5 0 0}$ & SJIF (Morocco) $=\mathbf{2 . 0 3 1}$ & &
\end{tabular}

208\%26_adf.ctrl-state\%3D59cnknyou_93 (Accessed: 10.02.2016).

3. (2016) Chislennost' detej s ogranichennymi vozmozhnostjami za 2009-2014 gody. Website:

www.stat.gov.kz/faces/wcnav_externalId/home NumbersSocialPolicy? afrLoop $=26198233645$ 932217\#\%40\%3F afrLoop\%3D261982336459 32217\%26_adf.ctrl-state\%3D59cnknyou_214 (Accessed: 10.02.16)

4. (2016) National bank. Available: www.nationalbank.kz/?docid=178\&switch=rus sian (Accessed: 10.02.2016).

5. Khamzina ZA (2015) Voprosy realizacii konstitucionnyh social'nyh garantij sem'i i rebenka. Vestnik Kazahskogo nacional'nogo pedagogicheskogo universiteta imeni Abaja, serija «Jurisprudencija», №2 (40), 2015. pp. 6772.

6. Khamzina ZA (2016) O privedenii razmerov social'nyh vyplat do urovnja prozhitochnogo minimuma. Informacionnyj portal Zakon.kz Available:

online.zakon.kz/Document/?doc id=31544697 (Accessed: 10.02.2016).

7. (2015) Doklad o polozhenii detej v Respublike Kazahstan, podgotovlen Komitetom po ohrane prav detej MON RK, pp. 49-50. Available: www.bala-kkk.kz/sites/default/files/upload/ files $/ \% 20 \% 204.12 .2015 . \operatorname{doc} \% 2 \mathrm{~B} \% 2 \mathrm{~B} \% 2 \mathrm{~B} \% 28$ 1\%29.pdf (Accessed: 10.02.2016).

8. Khamzina ZA (2016) Novyj Trudovoj kodeks o social'no-trudovyh pravah lic s semejnymi objazannostjami, nesovershennoletnih i ne tol'ko... Informacionnyj portal Zakon.kz. Available: www.zakon.kz/4769851-novyjj-trudovojjkodeks-o-socialno.html (Accessed: 10.02.2016).

9. (2016) Zarabotnaja plata rabotnikov po professijam i dolzhnostjam v 2015 godu. Available:

www.stat.gov.kz/faces/mobileHomePage?_afrL oop $=26043464933564670 \# \% 2$ Foracle $\% 2$ Fweb center $\% 2$ Fportalapp $\% 2$ Fpages $\% 2$ Fnavigationrenderer.jspx $\% 40 \% 3 \mathrm{~F}$ adf.ctrlstate\%3D15qrh0yc4r_25

(Accessed: 10.02.2016)

10. (2016) OECD, Social spending (indicator). doi: 10.1787/7497563b-en (Accessed: 26 Jan 2016).

11. (2016) Available: www.meta.kz/novosti/kazakhstan/735223-v2013-godu-v-kazahstane-na-socialnoeobespechenie-i-socialnuyu-pomosch-budetizrashodovano-136-trln-tenge.html (Accessed: 10.02.16)

12. (2016)

Available: www.oecdbetterlifeindex.org/ru/topics/incomeru/ (Accessed: 10.02.16).

13. (2016) Kratkij statisticheskij bjulleten' «Social'no-jekonomicheskoe razvitie Respubliki Kazahstan» soderzhit osnovnye pokazateli razvitija jekonomiki i social'noj sfery v janvaredekabre 2015 goda. №12 (dekabr') 2015, Astana, 2016. - pp. 83. 